\title{
Die Welthandelsorganisation (WTO) und demokratische Legitimität
}

Globale Ordnung zur Regelung wirtschaftlicher Interdependenzen und ihre Auswirkungen auf territorial organisierte Demokratie

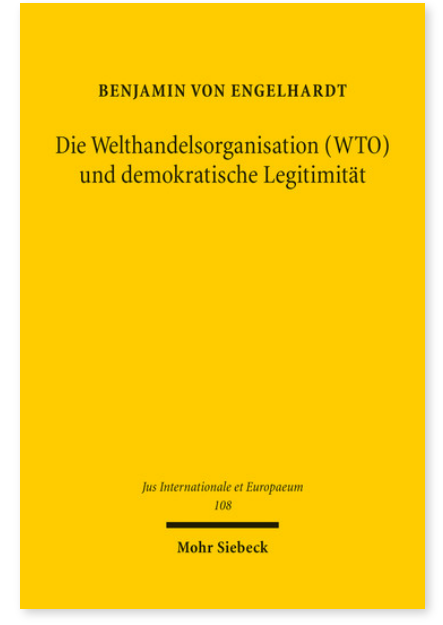

2016. XI, 347 Seiten. JusIntEu 108

ISBN 978-3-16-154070-7

DOI 10.1628/978-3-16-154070-7

eBook PDF $89,00 €$

ISBN 978-3-16-154069-1

fadengeheftete Broschur 89,00€
Der WTO wird vielfach ein Mangel an demokratischer Legitimität vorgeworfen. Benjamin von Engelhardt schlägt vor dem Hintergrund dieser Problematik einen Perspektivenwechsel vor: Müssen Staaten ihre Handlungen nur gegenüber dem eigenen Volk rechtfertigen oder gegenüber allen Betroffenen? Wenn allen Menschen die gleiche Würde zugeschrieben wird, kann nur Letzteres gelten. Wie lassen sich dann aber grenzüberschreitende externe Wirkungen, die gerade im Wirtschaftsbereich zunehmend unvermeidbar sind, demokratisch legitimieren? Föderal orientierte Kosmopolitiker leiten daraus die Notwendigkeit eines Weltstaates ab, der alle Betroffenen umfasst. Das WTO-Recht bietet eine alternative Lösung, indem es zwar die demokratisch nicht legitimierten externen Wirkungen nationaler Handlungen untersagt,

Regulierungszuständigkeiten aber auf nationaler Ebene belässt. Dieser Ansatz durchzieht eine Reihe eingehend analysierter WTO-Schiedssprüche und kann als Auslegungsmaxime zur Anwendung kommen.

Benjamin von Engelhardt Geboren 1978; Studium der Rechtswissenschaften mit wirtschaftswissenschaftlicher Zusatzausbildung in Bayreuth, Grenoble (Maîtrise en Droit) und Freiburg; Referendariat in Berlin und New York; Dissertation an der Humboldt-Universität zu Berlin, Gastforscher an der Harvard Law School. 2009-10 im Präsidium der Leuphana Universität Lüneburg; seit 2010 Referent im Bundesministerium für Wirtschaft und Energie, 2011-15 abgeordnet an die Ständige Vertretung Deutschlands bei der EU in Brüssel.
Jetzt bestellen:
https://mohrsiebeck.com/buch/die-welthandelsorganisation-wto-und-demokratische-legitimitaet-9783161540707?
no_cache=1
order@mohrsiebeck.com
Telefon: +49 (0)7071-923-17
Telefax: +49 (0)7071-51104 